\title{
Dispositivos de Escuta de Adolescentes Privados de Liberdade e de Agentes Socioeducativos*
}

\author{
Katia Tarouquella Brasil ${ }^{1, * *}$ (D, Sandra Francesca Conte de Almeida ${ }^{1}$ (D, \\ Jéssica Emanoeli Moreira da $\operatorname{Costa}^{2}$ (D) \& Valérie Ganem ${ }^{3}$ (D) \\ ${ }^{1}$ Universidade de Brasília, Brasilia, DF, Brasil \\ ${ }^{2}$ Secretaria de Saúde do Distrito Federal, Brasilia, DF, Brasil \\ ${ }^{3}$ Université Sorbonne Paris Nord, Paris, França
}

\begin{abstract}
RESUMO - Este estudo objetivou evidenciar um método de intervenção triangular na socioeducação. Foram implementados três dispositivos metodológicos: um plantão psicológico de escuta individual, um de grupo de fala com adolescentes e uma intervenção em Psicodinâmica do Trabalho com os agentes socioeducativos. A escuta dos adolescentes apontou como a violência comparece na relação entre eles e os adultos, entre eles e os pares e no espaço institucional. Por outro lado, a escuta dos agentes possibilitou situar como a violência permeia as situações de trabalho. A clínica ampliada, no contexto institucional, permitiu vislumbrar o lugar da violência na dinâmica relacional intersubjetiva, seus impactos psíquicos e os riscos à saúde mental dos sujeitos.
\end{abstract}

PALAVRAS-CHAVE: socioeducação, plantão psicológico, grupo, violência, psicodinâmica do trabalho

\section{Listening Devices for Adolescents Deprived of Liberty and Socio-Educational Agents}

\begin{abstract}
This study aimed to show a triangular intervention method in socio-education. Three methodological devices were implemented: a psychological call for individual listening, one for a speech group with adolescents and an intervention in Psychodynamics of Work with socio-educational agents. Listening to adolescents pointed out how violence appears in the relationship between them and adults, between them and peers and in the institutional space. On the other hand, listening to the agents made it possible to situate how violence permeates work situations. The expanded clinic, in the institutional context, allowed a glimpse of the place of violence in the inter-subjective relational dynamics, its psychic impacts and the risks to the subjects' mental health.
\end{abstract}

KEYWORDS: socio-education, psychological call, group; violence, psychodynamics of work

A pesquisa aqui apresentada constituiu-se a partir de dois eixos de investigação. O primeiro refere-se ao lugar da violência na dinâmica psíquica dos adolescentes que passam ao ato de forma violenta; o segundo diz respeito ao trabalho em um contexto de violência e seus impactos na saúde mental dos trabalhadores, na perspectiva da Psicodinâmica do Trabalho.
A violência é compreendida como uma conduta que coloca em ato a intenção de destruição ou alteração do outro, como objeto, mesmo que esse não tenha consciência da intenção (Dejours, 1999). Nessa perspectiva, Dejours considera importante distinguir no trabalho a violência reativa da violência ativa. A violência reativa é uma reação subjetiva descontrolada e funciona como uma resposta

\footnotetext{
* Apoio: FAP/DF. Edital 03/2015 - Demanda Espontânea, protocolo: 4525.25.30114.07072015.

** E-mail: ktarouquella@gmail.com

- Submetido: 10/10/2019; Revisado: 21/01/2020; Aceito: 23/03/2020.
} 
impulsiva a injustiças ou sofrimentos oriundos do ambiente de trabalho. Ela aparece como uma reação do aparelho psíquico, pois a identidade do sujeito está ameaçada. Tal cenário comparece em diversas situações como no vandalismo, sabotagem, ataques, etc.

A violência ativa ou actionnelle, como designada por Dejours (1999, 2007), revela uma intenção premeditada, uma vontade deliberada que está relacionada à liberdade do sujeito que põe em ato, intencionalmente, o prazer antecipado de fazer o outro sofrer, de agredi-lo, de lhe causar dano. Ela implica no exercício da liberdade e da vontade, é intencional e não impulsiva, ao contrário, é submetida ao princípio de realidade como, por exemplo, condutas sádicas, ataques premeditados, etc. Ao tratar da violência no trabalho, tal como a entendemos com Dejours, é preciso apontar que ela coloca em jogo a identidade do sujeito e também sua implicação no contexto social e laboral.

A hipótese subjacente da pesquisa foi a de que escutar os adolescentes em privação de liberdade e os agentes socioeducativos permitiria identificar o lugar da violência na instituição, nas relações interpessoais e na sua inscrição subjetiva, ideia diretriz inferida a partir de alguns estudos (Codinhoto, 2014; Costa et al., 2017; Gurski \& Strzykalski, 2018). A escuta dos adolescentes poderia apontar como a violência comparece na relação desses jovens com os adultos, entre eles e no espaço institucional. Por outro lado, a escuta dos agentes socioeducativos possibilitaria situar como a violência se integra ao trabalho cotidiano desses profissionais. Assim, para alcançar o objetivo de apreender e discutir as condutas violentas adotadas pelos dois grupos e seu impacto na subjetividade dos sujeitos, o dispositivo da escuta clínica, individual e grupal, mostrou-se apropriado e pertinente.

\section{ADOLESCENTES EM CONFLITOS COM A LEI}

A temática da violência, no que se refere à adolescência e à juventude, atualmente vem preocupando estudiosos, tanto em termos de sua frequência quanto de sua intensidade, o que exige uma reflexão sobre as suas múltiplas causalidades e situações de seu agravamento (Patias et al., 2016). Nenhuma análise sobre esse tema pode reduzir a complexidade da violência, principalmente aquelas nas quais os jovens são os principais envolvidos e que implicam em aspectos psíquicos, relacionais e mesmo políticos e sociais. Abordar essa questão requer considerar a inter-relação entre todos esses fatores e, principalmente, buscar compreender seu impacto junto à população jovem (Brasil et al., 2016; Scisleski et al., 2015).

Se por um lado nos deparamos com a complexidade do tema violência, por outro, estudos realizados por diferentes autores e perspectivas teóricas (Broide, 2010; Dias, 2003) assinalam para a relação entre poder e violência, entre violência e subjetividade e entre violência e sociedade. A violência, contudo, principalmente no que se refere à juventude, não pode ser apenas compreendida pela agressividade inerente ao ser humano, como algo constitutivo da subjetividade, particularmente nesse período do desenvolvimento, nem tão pouco atribuída somente a fatores externos aos sujeitos como conflitos sociais e exclusão social, baseados em uma possível relação entre poder e violência. Ela supõe uma análise que possa integrar essas duas dimensões e que revele a extensão da sua complexidade.

Com relação à adolescência e à juventude, pode-se colocar em discussão algumas questões relativas ao funcionamento psíquico desses sujeitos que passam ao ato de forma violenta. $\mathrm{O}$ que a passagem ao ato pode nos indicar sobre a dinâmica psíquica desses adolescentes? No contexto da adolescência vulnerável, de que violência se trata?

A adolescência coloca em perspectiva uma reorganização da identidade corporal, psicológica e sexual (Gutton, 1990;
Marty, 2006), ao mesmo tempo em que aponta para a fragilidade narcísica de um momento de remanejamento pulsional que pode levar o adolescente a agir para sair da percepção de ser agido, no sentido da intensidade das transformações. Por um lado, pode-se sublinhar a interação entre a violência pubertária e o registro sublimatório, que permitiria a renúncia à satisfação pulsional imediata (Marty, 2012). Por outro lado, trata-se também de distinguir a violência agida das condutas delituosas da violência interna, de essência pubertária, que envolve as transformações corporais, por vezes vividas como verdadeiros traumatismos (Costa et al., 2017).

Configurando hipóteses de natureza metapsicológica, Jeammet (2006) propõe como condição essencial para emergência da violência o ataque ao narcisismo e a defesa contra o que é percebido como uma ameaça à identidade, considerando que as suas diferentes modalidades de expressão apontam para os remanejamentos defensivos do eu e para a capacidade de ligação com a libido, abrindo o campo da agressividade e sua articulação com os fantasmas sádicos e masoquistas.

Marty (2012) compreende a passagem ao ato pelo seu valor econômico de evitação do conflito interno, na medida em que o objeto não é identificado no interior de si, mas na realidade externa, no outro. De toda forma, a questão da passagem ao ato toca dimensões narcísicas e objetais bem como a forma com que o sujeito lida com a agressão, suas raízes psíquicas e a ligação com o impulso destrutivo interior. Mas também se refere a uma violência como defesa em relação às injustiças sociais, à precariedade de vida e do trabalho dos pais. Por isso é preciso analisar os elementos psíquicos e traumáticos relacionados à violência, os aspectos sociais e econômicos, bem como o lugar que ela assume nas relações de trabalho. 
A violência atuada e/ou vivida pelos jovens em situação de risco coloca em relevo o traumatismo, aspecto fundamental ligado à questão da violência, seja ela vivida ou atuada, e que precisa ser mais explorado. Nessa perspectiva, o traumático relaciona-se com o impacto psíquico e diz respeito tanto às angústias presentes no processo de constituição do sujeito quanto às experiências vividas na realidade, que não são passíveis de serem representadas, implantando um vazio de simbolização (Marty, 2006).

A relação entre violência, adolescência e juventude foi recentemente evidenciada por Waiselfisz (2015), no Mapa da Violência, que aponta a situação, no Brasil, do envolvimento de jovens com a violência, tanto como promotores quanto suas vítimas. Segundo o Sistema Nacional de Atendimento Socioeducativo (SINASE), no levantamento anual de 2014, os adolescentes (12-18 anos) representavam aproximadamente 24 milhões da população brasileira, sendo que 24.628 adolescentes e jovens (12 a 21 anos) estavam em restrição e privação de liberdade (internação, internação provisória e semiliberdade). Ou seja, o percentual de adolescentes que estava cumprindo alguma medida socioeducativa no Brasil representava $0,1 \%$ dos adolescentes da população de 12 a 18 anos. Em contraponto, segundo o Mapa, o número de óbitos por causas externas cresceu em 2013 em proporção alarmante, tendo tido um aumento de $29 \%$. As causas externas representavam 56,6\% do total de mortes na faixa de 1 a 19 anos de idade, com uma taxa de mortes por homicídio de $13,9 \%$, o que significa que adolescentes e jovens são muito mais alvo e vítimas da violência do que seus agentes e isso é algo importante a ser considerado.

$\mathrm{O}$ ato infracional é resultado de causa multifatorial, que tem a ver com problemas vivenciados no âmbito social, como contextos de vulnerabilidade, preconceito, desigualdade, dentre outros, e também com certas condições que permeiam o funcionamento psíquico dos adolescentes transgressores (em sua grande maioria negros e oriundos das camadas mais empobrecidas da população), e que é marcado de forma traumática pelas vivências internas do processo de adolescência, pela exclusão social e pelo racismo.

Nosso entendimento, na perspectiva teórica aqui adotada, aponta que nas problemáticas do agir o mundo interno é expelido sobre os objetos externos e a violência é projetada. Nessa direção, é importante identificar os desafios clínicos e educacionais aí postos para trabalhar e intervir junto aos profissionais da socioeducação, que atuam diretamente com adolescentes em conflito com a lei.

\section{O TRABALHO DOS AGENTES DE REINTEGRAÇÃO SOCIOEDUCATIVA}

O trabalho dos agentes de reintegração socioeducativa junto aos adolescentes em conflito com a lei produz um impacto subjetivo nos profissionais, tendo em vista os afastamentos do trabalho por adoecimento, as noites sem dormir e o modo como a vida cotidiana é invadida pelo medo de serem reconhecidos na rua por algum adolescente que tenha saído da unidade de internação. Albuquerque (2017) acrescenta que esses profissionais estão constantemente expostos a ameaças, provocações, tentativas de agressão e alvos de lançamento de objetos, ao mesmo tempo em que a relação com os adolescentes cria, em algumas situações, um vínculo afetivo de muita importância para o cumprimento da medida (Craidy \& Szuchman, 2017).

Assim sendo, compreende-se o impacto que tais vicissitudes relacionais cotidianas têm na subjetividade, aqui entendida na perspectiva de Guattari e Rolnik (1996) como não reduzida ao conceito de identidade ou às identificações (primárias e/ou secundárias). Tratam-se, antes, de sistemas de conexão direta ente as instâncias sociais, produtivas e de controle social e as instâncias psíquicas, que definem a maneira de perceber o mundo. Assim, a subjetividade "não é passível de totalização ou de centralização no indivíduo", pois ela "é essencialmente fabricada e modelada no registro do social" (Guattari \& Rolnik, 1996, p. 31).

O trabalho dos agentes socioeducativos é orientado por uma referência presente no Sistema Nacional de Atendimento Socioeducativo (SINASE) e se caracteriza por atividades de acompanhamento, de guarda e de segurança de adolescentes que cumprem medidas socioeducativas por terem cometido atos infracionais, previstas no Estatuto da Criança e do Adolescente (ECA; Brasil, Lei Federal n. 8069/90).

Os agentes socioeducativos integram uma equipe interdisciplinar composta por psicólogos, assistentes sociais, professores, pedagogos e outras especialidades. Eles têm uma atuação que comporta uma dupla dimensão, a saber, educativa e de sanção, pois são convocados a executarem práticas relacionadas à socioeducação, mas também são demandados a desempenharem intervenções relacionadas à vigilância e segurança nas instituições. A medida de privação de liberdade, dada a sua proximidade com o sistema prisional, leva esses trabalhadores a manejarem duas posições nem sempre conciliáveis: garantir a segurança na unidade de internação de adolescentes e exercer uma ação socioeducativa (Herculano \& Gonçalves, 2011). Diante desse quadro, entende-se que esses trabalhadores são impactados pela natureza do trabalho, que lhes demanda funções contraditórias e os colocam em uma posição de ambiguidade com repercussões subjetivas inegáveis. Frente à complexidade do sistema de privação de liberdade, o estudo objetivou evidenciar um método de intervenção triangular na socioeducação como uma forma de identificar o lugar da violência nas relações institucionais. 


\section{MÉTODO}

O estudo aqui relatado faz parte de uma investigação mais ampla intitulada Violência e passagem ao ato: o discurso dos adolescentes em conflito com a lei e dos profissionais das medidas socioeducativas, apoiado pela Fundação de Apoio à Pesquisa do Distrito Federal, FAP/DF, e foi aprovado pelo Comitê de Ética em Pesquisa da Universidade Católica de Brasília (CAAE: 50960115.0.0000.0029). O nome dos participantes foi mantido no anonimato, a participação foi voluntária e os adolescentes assinaram o Termo de Consentimento Livre e Esclarecido (TCLE), com a autorização do Juiz da vara de execução de medidas socioeducativas do Distrito Federal.

Naquele contexto, foi proposta uma intervenção em Psicodinâmica do Trabalho (PDT), que é uma disciplina clínica que se sustenta na descrição e no conhecimento das relações de trabalho e em intervenções nessas relações com o foco na saúde mental dos trabalhadores. Trata-se de uma disciplina cuja concepção de sujeito se apoia na teoria psicanalítica e na teoria social (Dejours, 2013).

A demanda institucional era a de que os profissionais fossem escutados nos desafios do trabalho com os jovens privados de liberdade. Assim, por meio do dispositivo da escuta clínica constitui-se um espaço de fala, que contou com a participação de um grupo de voluntários. Os objetivos da intervenção eram os de investigar as repercussões subjetivas do trabalho dos agentes, como eles lidavam com os adolescentes em conflito com a lei e como se sentiam mobilizados por essa relação, de modo a perceberem o trabalho como constituinte da relação do sujeito com sua identidade pessoal e profissional e, portanto, com impacto na sua subjetividade, na atuação na instituição e na relação com os adolescentes.

A intervenção em PDT, junto aos agentes socioeducativos, seguiu as seguintes etapas:

a. as pré-enquetes: consistiram em cinco encontros, com cinco equipes diferentes. Esses encontros objetivaram alcançar a adesão de um número significativo de voluntários e oferecer um espaço de escuta das suas demandas;

b. as enquetes: foram realizados cinco encontros nos quais houve um redimensionamento das demandas e um aprofundamento das problemáticas apresentadas pelos grupos. Os encontros grupais duravam aproximadamente uma hora e meia e ocorreram na própria Unidade de Internação, em uma sala dentro da escola, cedida pela Direção;

c. a análise das enquetes: incidiu sobre o material produzido no espaço coletivo de fala, onde foi possível aos trabalhadores expressarem as suas vivências subjetivas em relação ao trabalho junto aos adolescentes em conflito com a lei; d. a observação clínica: foram resgatadas as interações interpessoais e grupais ocorridas entre os pesquisadores e os grupos de trabalhadores para articulá-las com os comentários de cada sessão, de modo a facilitar a compreensão da dinâmica específica do grupo;

e. a interpretação: nessa fase, que tem como referencial a análise das demandas, o material das enquetes e as observações clínicas, os pesquisadores buscaram dar sentido aos elementos subjetivos que emergiram ao longo das sessões;

f. a devolutiva e a validação do relatório: nessa última etapa, o material produzido no espaço coletivo foi apresentado aos participantes sob a forma de um relatório. Os trabalhadores puderam analisá-lo e se apropriar do seu conteúdo, como também reagir e sugerir modificações e inclusões.

Concomitantemente à intervenção realizada junto aos agentes socioeducativos realizou-se a pesquisa-intervenção junto aos adolescentes, que ocorreu em um espaço grupal e em um espaço individual. Na intervenção grupal foi proposto um grupo de fala, adotando-se o dispositivo metodológico da Conversação. Tal dispositivo foi criado por Miller (2003) e pode ser compreendido como um tipo de associação livre que obtém êxito, uma associação livre coletivizada, com a finalidade de se criar as condições para que não ocorra uma escuta passiva, para que os sujeitos se sintam convocados a participar, a associar livremente (Fagundes \& Almeida, 2016). Marcos e Mendonça (2017) destacam que o importante nesse dispositivo é a palavra, que oportuniza circular no grupo algo da ordem do inconsciente do sujeito, palavra que também faz laço social.

Da intervenção individual, nomeada Plantão Psicológico, participaram alguns adolescentes dos grupos de Conversação e adolescentes que não quiseram participar ou permanecer nos mesmos. O Plantão Psicológico é um dispositivo de atendimento psicológico individual que visa oferecer a quem o procura o acolhimento e a escuta de sua demanda imediata, de modo a ajudar o sujeito a elaborar a sua urgência, a mobilizar os seus recursos e a reconhecer os seus limites (Mahfoud, 1999; Rocha, 2011).

\section{Procedimentos}

\section{O Dispositivo da Conversação - Intervenção Grupal}

Os grupos de Conversação com os adolescentes ocorreram na Unidade de Internação e foram conduzidos por três estagiárias do curso de Psicologia, supervisionadas por uma psicóloga-pesquisadora. Foram realizados sete encontros, com duração de uma hora e vinte minutos, com dois grupos compostos, cada um deles, por sete meninos 
adolescentes de 16 a 19 anos incompletos e que cumpriam medida socioeducativa de internação. Todas as falas foram gravadas em áudio e posteriormente transcritas. Os sujeitos foram indicados pela Instituição e convidados a participar da pesquisa. A proposta lhes foi apresentada e aqueles que se interessaram integraram o grupo como participantes voluntários. Foram excluídos os adolescentes que tinham rivalidade ou alguma espécie de rixa entre si.

\section{O Plantão Psicológico: Intervenção Individual}

Os atendimentos individuais de escuta clínica, realizados sem hora previamente marcada, com sessões de duração de aproximadamente 50 minutos, ocorreram em um espaço privado. Foram realizados 22 atendimentos individuais, com a participação de 14 sujeitos, inicialmente encaminhados pela Direção da escola, com o acordo da Direção da Unidade de Internação. Todavia, aos poucos, outros adolescentes que não haviam sido indicados souberam dos atendimentos e espontaneamente pediram para "ver a psicóloga" no dia do "Plantão Psicológico". Os plantões eram supervisionados por uma psicanalista integrante do grupo de pesquisa e o registro das sessões foi feito sob a forma de anotações escritas.

Pôde-se observar que ao longo dos encontros, nas intervenções em grupo e nas individuais com os adolescentes em conflito com a lei, os jovens puderam expressar em suas falas vivências de raiva, desamparo, indignação, colocando em evidência o impacto da violência na relação com os agentes, no contexto institucional, o desprezo da sociedade e o descrédito dos quais eles são alvo.

\section{Organização e Análise do Material Coletado}

Inicialmente, para organizar os dados coletados e posteriormente transcritos, os pesquisadores debruçaram-se sobre o material produzido pelos adolescentes nos Grupos de Conversação e no Plantão Psicológico e pelos agentes socioeducativos na intervenção em Psicodinâmica do Trabalho, com vistas a identificar, por meio de uma leitura flutuante dos dados, núcleos de sentido e de significação compartilhados, comuns ou tangenciados pelos dois grupos de participantes nos três dispositivos de escuta clínica utilizados na pesquisa-intervenção. Assim, buscou-se nas variadas fontes de informação ou de "triangulação" na produção e análise dos dados, como apontam Oliveira e al. (2019), uma estratégia metodológica para investigar as experiências e vivências dos sujeitos na socioeducação.

Posteriormente, os pesquisadores retornaram ao material escrito e o analisaram detalhadamente, buscando então elaborar e construir algumas zonas de sentido (González Rey, 2007) entrelaçadas nos relatos dos agentes e dos adolescentes. Para González Rey, o sentido é constitutivo da subjetividade e integra os mais diferentes registros sociais, resultando numa organização subjetiva marcada pelas emoções, processos simbólicos e significados.

No processo de análise, interpelação e interpretação dos dados, chegou-se à elaboração de três zonas de sentido que colocam em cena a violência atuada e a destrutividade de adolescentes e agentes socioeducativos no contexto institucional: a violência na instituição, a falta de sentido no trabalho e a falta de um lugar no tecido social.

\section{RESULTADOS E DISCUSSÃO}

A violência que atravessava a Unidade de Internação para adolescentes ganhou "visibilidade" nas narrativas dos profissionais da socioeducação e dos jovens, nos espaços grupais e individual de escuta e de fala. A intervenção triangular no contexto institucional permitiu apreender a posição subjetiva dos dois grupos e o lugar da violência na Unidade, fenômeno que está fortemente presente nas relações interpessoais e intergrupais (dos adolescentes com os agentes e vice-versa). Assim, por meio dos dispositivos utilizados, diversas manifestações da violência puderam ser reveladas e colocadas em palavras no circuito de trocas simbólicas, nos dois grupos. Na escuta individual, isto é, nos plantões psicológicos, sobressaiu-se a inscrição subjetiva da violência na história de vida dos jovens e sua função psíquica e relacional.

\section{As Zonas de Sentido}

\section{A Violência na Instituição}

As falas a seguir, escutadas no espaço coletivo dos profissionais, relata um ataque dos adolescentes à Unidade de Internação e como a violência reativa pode invadir a cena institucional e se constituir em uma denúncia do modo de relação entre os diferentes sujeitos:

“Tentaram botar fogo para se matarem. Somos bombeiros". (G).

"Se você fala (para o menino) que não vai entrar aqui com drogas, eles ameaçam te matar. Um agente já teve a casa cheia de tiros". (A).

"Sinto mais medo fora que aqui dentro. Tenho medo de encontrar um menino lá fora”. (B).

Por se sentirem atacados, os agentes manifestam a necessidade de reagir, mas também relatam a dificuldade de conterem a sua própria raiva e destrutividade como reação à passagem ao ato dos adolescentes: "Aqui você precisa fazer contenção do adolescente sem machucá-lo. Tenho dificuldade de conter o menino sem machucar". (G).

Essa fala parece atravessada por uma certa ambivalência emocional, pois o profissional que se vê atacado pelo adolescente se percebe como tendo de conter tanto a violência do adolescente quanto a sua própria violência 
reativa, que pode se expressar até mesmo pelo embate no corpo-a-corpo. O contato com o corpo do menino, pela via da contenção física, é um fator desestabilizador e que provoca angústia nos agentes, pois o limite entre conter o outro e feri-lo nem sempre é claro e precisamente delimitado.

Nesse cenário, denúncias de locais de tortura e de violência institucionalizadas foram escutadas, uma prática que se perpetua em muitas instituições da mesma natureza ou semelhantes e que se configuram como práticas "silenciadas", seja pela sua absoluta ilegalidade como também pela sua "invisibilidade". Assim se apresenta o relato de um adolescente, no grupo de Conversação, sobre a violência atribuída aos agentes: "Os cara soca nois lá naquele quarto lá".

Ao denunciar no espaço grupal a existência de um quarto na instituição em que violências ocorreriam sem que fossem vistas, os adolescentes apontam e reconhecem um inimigo comum, personificado nos agentes socioeducativos, cujas práticas violentas e "invisíveis", na percepção dos adolescentes, contavam com a complacência da instituição.

O mal-estar na relação entre os adolescentes e os agentes e a violência que a atravessa foi revelado no Plantão Psicológico, na fala a seguir: “... os agentes, por exemplo, uma coisa que não tem nada a ver eles ficar sem motivo pra atrasar nós, pra nós perder nosso saidão, aí o cara já tá com raiva, ai sai com mais raiva ainda, sai pior do que entrou".

Esta fala situa o "saídão" (dia em que o juiz os autoriza passar um fim de semana fora da instituição) como uma ocasião bastante valorizada e esperada pelos adolescentes, pois significa experimentar novamente a liberdade, se encontrar com os amigos e com os familiares e comemorar algumas datas festivas, como o Dia das Mães ou o Natal. Eles se queixam que justamente nesse dia por vezes os agentes lhes atrasam a saída, como se houvesse, aí, um jogo de forças que revela a violência mascarada da instituição: “... .no meu ponto de vista, ... aqui tá todo mundo do mesmo jeito, todo mundo de sandália, ninguém é mais que ninguém, nem menos. Ai é a mesma coisa..."

Uma das questões que parece se impor drasticamente no espaço institucional é a uniformização dos sujeitos, com a negação das diferenças, e a invisibilidade que toma as cenas de violência real e simbólica, pela via do controle dos corpos, da expressão e das subjetividades.

\section{A Falta de Sentido no Trabalho}

Os agentes apresentam um discurso queixoso, atravessado pelo descrédito e pela falta de sentido no seu trabalho: "Aqui nunca vai ressocializar alguém, porque aqui de cada sete se salva um, salva". (L). A ideia de que a ressocialização é ineficaz está fortemente presente nos diversos relatos, tornando evidente a falta de sentido atribuída ao trabalho, o que contribui com o sofrimento psíquico dos profissionais e com a prática de algumas condutas abusivas, derivadas de uma violência reativa ao contexto institucional.
Enfatiza-se que um dos grandes benefícios da intervenção em Psicodinâmica do Trabalho foi compreender o sentido das condutas do ponto de vista daqueles que as adotam, isto é, o caráter reativo da violência dos profissionais, em face da falta de sentido e de reconhecimento atribuída ao seu trabalho. Entende-se que a percepção dessa situação produz efeitos psíquicos devastadores nos profissionais e sobre isso eles puderam falar no coletivo:

"Aqui é tensão: são 100 internos para 5 agentes. Se tiver briga não vamos dar conta deles. Se tiver medo, a pessoa não pode trabalhar aqui, nem receio de ser fisicamente agredida, pois o menino pode querer fazer com a gente o que fazia na rua. Porém, isso não mete medo na gente”. (G).

A fala anterior demonstra o medo com o qual os profissionais são confrontados no trabalho com os adolescentes. Diante desse quadro, para evitar que o medo se instalasse, os agentes utilizaram a cooperação entre os pares, apoiada nas relações de confiança e de ajuda mútua, organizando-se em torno da imposição de uma disciplina rígida, praticamente carcerária, no controle dos adolescentes. Uma regra disciplinar que possuía a função de dar suporte imaginário aos trabalhadores na lida com o sofrimento e na tentativa de não sucumbirem ao medo e à violência dos adolescentes, tal como relatado: “... se os internos começarem a perceber que vai ter disciplina, minimizam as ações" / "... se tirarem a disciplina, eles (os adolescentes) irão tomar conta da cadeia”. (A).

Nesse contexto, a disciplina ganha contornos punitivos, pois permite que os mesmos trabalhadores, responsáveis pelas medidas socioeducativas, possam também exercer a função de controlar, de dominar os atos violentos advindos dos jovens em conflito com a lei, situação que pode comprometer o caráter (re)educativo de seu trabalho, como relatado na seguinte fala:

“Tem que ter disciplina, senão alguém domina e alguém
é dominado. A gente precisa se sobrepor, senão fica a
mesma coisa de lá de fora. Não é violência, é disciplina, e
não é punição. Aqui é muito restrito. A gente está falando
de adolescente. Temos que falar: moleque, vou tirar seu
videogame... somos muito acusados de sermos violentos”. (C).

Na perspectiva dos agentes, a disciplina rigorosa é vista como uma estratégia de cooperação frente aos perigos e ao medo diante dos adolescentes, permitindo que os trabalhadores se sintam mais poderosos e protegidos na relação com os adolescentes no convívio do espaço institucional.

Os relatos escutados no espaço coletivo de fala denotaram sofrimento no trabalho. Dejours et al. (1994) defendem que a manifestação do sofrimento dos trabalhadores possibilita o acesso a uma parte do trabalho que nem sempre é revelada. Esse é um ponto fundamental para a Psicodinâmica do Trabalho, pois é pela via da elaboração simbólica do sofrimento no 
espaço coletivo que os trabalhadores podem transformar sua experiência com o trabalho e reconhecer como a violência entra em cena para abrandar medos e angústias. Ao mesmo tempo, no caso dos agentes, permitiu revelar como a vivência do coletivo, naquele trabalho, tinha a função de reduzir o impacto dos fatores conflitivos que poderiam desencadear sofrimento, como se observa no relato a seguir: "Quando estou estressado, precisando sair um pouco para esfriar a cabeça, nessa hora é que a equipe entra, cuidando do meu módulo, enquanto eu saio para dar uma espairecida". (A).

$\mathrm{O}$ fortalecimento do coletivo permite, assim, enfrentar as dificuldades e buscar pelo equilíbrio psíquico (Lancman \& Uchida, 2003). O trabalho coletivo, pela troca de experiências, escuta do outro e pela fala sobre o próprio trabalho, possibilita a construção de regras comuns, entendendo-se que as regras de trabalho construídas coletivamente são modos de viver em coletividade e contribuem para sustentar a atividade de trabalho (Dejours \& Delory-Momberger, 2010).

\section{A Falta de um Lugar no Tecido Social}

Pellegrino (2004) afirma que para a vida social ser suportável, ela precisa estar irrigada de princípios de justiça, de equidade e de respeito pela pessoa humana. Os adolescentes em privação de liberdade nem sempre sentem que possuem direitos e o sentimento de exclusão marca a relação deles com o tecido social, do qual se sentem pouco integrados, como pode ser observado nas falas a seguir:

“.... a sociedade lá fora vê quem tá aqui de dentro como bicho, pô... porque tipo o pessoal pra julgar, pra tacar a marreta em todo mundo aqui, ... agora pra ajudar, pra dar um estímulo, pra dar uma oportunidade não aparece ninguém entendeu"? (A).

“... todo mundo que ter uma coisa bacana hoje, uma jaqueta, então isso ai é o dinheiro. Infelizmente isso envolve o dinheiro né. Então como é que eu vou... eu pessoalmente quero andar legal, quero ter uma boa roupa, uma boa aparência, um bom carro, uma boa casa, se eu não tiver isso como é que eu vou construir uma família? Então infelizmente o dinheiro vem acima disso tudo...". (D).
“... melhor tráfico. Vai ficar roubando, se tu 'pode' compraro tênis mais doido, zerado, com a caixa e tirar onda ainda”. (G).

Quando a violência é expressa pelo agir, o medo é um companheiro na adolescência e paralisa a elaboração psíquica do pensar. Nesse cenário, o sofrimento psíquico supõe uma articulação entre a precariedade interna, subjetiva do sujeito, sua dificuldade de elaboração simbólica e a precariedade social, traduzida pelo adolescente como a falta de um lugar no mundo. Tendo em conta esse entendimento, os espaços coletivos e individuais de escuta e de fala oferecidos aos adolescentes, na Unidade de Internação, constituíram lugares nos quais o sofrimento pôde ser qualificado e a palavra tornar-se um meio privilegiado de comunicação com o outro, substituindo-se às passagens ao ato. Tais dispositivos permitiram ainda, apesar de certos limites impostos pelo contexto institucional e pela realidade psíquica dos adolescentes, uma maior elaboração simbólica das experiências vividas como traumáticas e a oportunidade, por mínima e provisória que fosse, de inscrição em um tecido social que se propunha a escutá-los e a reconhecê-los como sujeito.

Os adolescentes em conflito com a lei necessitam encontrar adultos que não fraquejem, que resistam à sua agressividade e destrutividade e que lhes sirvam de referência. Perante a falta de adultos que assumam esse lugar, o adolescente nem sempre conseguirá canalizar sua violência interna, seus medos e sua fragilidade atribuindo-lhes algum sentido culturalmente aceito.

A pesquisa em uma instituição de privação de liberdade apresenta vários desafios, como a desconfiança dos adolescentes e as barreiras da instituição. Contudo, esses desafios não devem ser um empecilho para as pesquisas nas instituições de privação de liberdade, de modo que seria interessante que uma intervenção nessas três dimensões pudesse ser implementada em outras instituições socioeducativas, como um modo de a pesquisa-intervenção contribuir para políticas públicas mais consistentes e um acompanhamento mais cuidadoso dos profissionais e dos adolescentes vinculados à socioeducação.

\section{CONSIDERAÇÕES FINAIS}

Sobre os agentes socioeducativos, pode-se dizer que no exercício de suas funções as condutas de violência (reativa, na maioria das vezes) pretendem impor submissão e obediência ao outro, no caso aos adolescentes, tornando-se um dispositivo de poder no trabalho e um meio de o sujeito não sucumbir ao medo. Ao investirem em um trabalho no qual, de um modo geral, não acreditam e não atribuem sentido, recorrem ao uso da violência como um instrumento de controle social e de opressão, cujos efeitos solapam a sua própria ação educativa e põem em risco a sua saúde mental.

Por sua vez, os adolescentes e jovens em conflito com a lei são herdeiros da exclusão social em que vivem suas famílias e para eles o reconhecimento de um lugar no tecido social passa por formas alternativas e igualmente excludentes que não se relacionam com o mundo do trabalho nem com a escola. Aliás, esta é vista, via de regra, como o lugar em que esses meninos conheceram as primeiras experiências de fracasso e de exclusão escolar (Brasil et al., 2016). A importância da escuta dos adolescentes em conflito com a lei e dos agentes de reintegração social foi, sobretudo, a de tirar da invisibilidade o sofrimento desses sujeitos, integrantes de um mesmo cenário institucional.

Vale a pena destacar que a Psicodinâmica do Trabalho proporcionou aos profissionais discussões em torno dos 
desafios do trabalho socioeducativo com adolescentes em conflito com a lei, permitiu escutarem-se em suas contradições e reconhecerem dificuldades e conflitos na relação com a instituição, com a aplicação das medidas socioeducativas e de controle social e nas interações com os adolescentes. A criação do espaço coletivo de fala permitiu recolocar o trabalho no centro das atenções e discutir os desafios inerentes ao trabalho no contexto da violência. Além disso, por meio da escuta clínica dos adolescentes e dos agentes, pôde-se vislumbrar o lugar da violência na dinâmica relacional, seus impactos psíquicos e riscos à saúde mental dos sujeitos.

\section{REFERÊNCIAS}

Brasil, K. T. R., Ferreira, T. S., Ferreira, R. M. A., \& Lima, H. T. S. (2016). Espaço escolar e violência: A fala dos adolescentes em situação de liberdade assistida. In K. T. Brasil \& D. Drieu (Orgs.), Mediação, simbolização e espaço grupal: Propostas de intervenção com adolescentes vulneráveis (pp. 51-70). Liber Livro/UNESCO.

Brasil. (1990). Lei no 8.069, de 13 de julho de 1990. Dispõe sobre o Estatuto da Criança e do Adolescente e dá outras providências. Diário Oficial da União. http:// www.planalto.gov.br/ccivil 03/ leis/18069.htm

Codinhoto, E. (2014). Cortinas de ferro: O trabalho real de socioeducadores de uma unidade socioeducativa do estado de Rondônia [Dissertação de mestrado]. Repositório da UNIR. http://www.ri.unir.br/jspui/bitstream/123456789/1313/1/ Elizangela\%20Codinhoto_Cortinas\%20de\%20ferro.pdf

Costa, J. E. M., Brasil, K. T., \& Ganem, V. (2017). O desafio do trabalho com adolescentes em conflito com a lei: Uma intervenção em psicodinâmica do trabalho. Psicologia em Estudo, 22(2), 165-173. https://doi.org/10.4025/psicolestud. v22i2.31869

Broide, J. (2010). Adolescência e violência: Criação de dispositivos clínicos no território conflagrado das periferias. Revista Psicologia Política, 10(19), 95-106.

Dejours, C. (2006). Aliénation et clinique du travail. Actuel Marx, $39(1), 123-144$

Dejours, C. (2007). Conjurer la violence. Travail, violence et santé. Payot.

Dejours, C. (2013). Subjetividade, trabalho e ação: Uma visão de conjunto. In Trabalho vivo: Trabalho e emancipação (tomo II, pp. 23-44). Paralelo 15

Dejours, C., Abdoucheli, E., \& Jayet, C. (1994). Psicodinâmica do trabalho: Contribuições da escola dejouriana à análise da relação prazer, sofrimento e trabalho. Atlas.

Dejours, C., \& Delory-Momberger, C. (2010). Le travail entre souffrance individuelle, intelligence collective et promesse d'émancipation. Le Sujet dans la Cité, 1(1), 59-72.

Dejours, C. \& Mello Neto, G. A. R. (2012). Psicodinâmica do trabalho e teoria da sedução. Psicologia em Estudo, 17(3),363371. https://doi.org/10.1590/S1413-73722012000300002

Dias, A. R. F. (2003). O discurso da violencia. Cortez.

Fagundes, C., \& Almeida, S. F. C. (2016). A nova ordem simbólica e suas repercussões na função docente, no Ensino Superior. In C. P. de Medeiros \& S. F. C. de Almeida (Orgs.), Psicanálise implicada: Educar e tratar o sujeito (pp. 65-89). Juruá.

Guattari, F., \& Rolnik, S. (1996). Micropolitica: Cartografias do desejo ( $4^{\mathrm{a}}$ ed.). Vozes.

Gurski, R., \& Strzykalski, S. (2018). A escuta psicanalítica de adolescentes em conflito com a lei: Que ética pode sustentar esta intervenção? Tempo Psicanalítico, 50(1), 72-98.

Gutton, P. (1990). Le pubertaire. PUF.

Herculano, J. A. H., \& Gonçalves, M. C. (2011). Educador social: Segurança e socioeducador, a conciliação. Serviço Social Revista, 14(1) 74-101. https://doi.org/10.5433/16794842.2011v14n1p74
Jeammet, P. (2006). As patologias do agir na adolescência. In M. Amaral (Org.), Educação, psicanálise e direito (pp. 22-56). Casa do Psicólogo.

Lancman, S., \& Uchida, S. (2003). Trabalho e subjetividade: O olhar da psicodinâmica do trabalho. Cadernos de Psicologia Social do Trabalho, 6, 79-90. http://pepsic.bvsalud.org/scielo. php?script=sci_arttext\&pid=S1516-37172003000200006\&ln $\mathrm{g}=\mathrm{pt} \& \mathrm{t} \operatorname{lng}=\mathrm{pt}$

Marco, C. M., \& Mendonça, R. L. (2017). A pesquisa-intervenção psicanalítica com adolescentes: O que elas nos dizem sobre gravidez e maternidade a partir da conversação. Psicologia em Revista, 23(2) 707-727. http://pepsic.bvsalud.org/pdf/per/ v23n2/v23n2a11.pdf

Mahfoud, M. (Org.). (1999). Plantão psicológico: Novos desafios. Companhia Ilimitada.

Marty, F. (2012). A função do agir na adolescência. In D. Amparo, S. F. C. Almeida, K. T. Brasil, M. I. G. Conceição, \& F. Marty (Orgs.), Adolescência e violência: Intervenção e estudo clínico, psicossociais e educacionais (pp 17-29). Liber Livros/Editora Universidade de Brasília.

Marty, F. (2006). Adolescência, violência e sociedade. Ágora: Estudos em Teoria Psicanalítica, 9(1), 119-131. https://doi. org/10.1590/S1516-14982006000100009

Miller, J.-A. et al. (2003). La pareja y el amor: Conversaciones clinicas com Jacques-Alain Miller en Barcelona. Paidós.

Patias, N. D., Silva, D. G., \& Dell'Aglio, D. D. (2016). Exposição de adolescentes à violência em diferentes contextos: Relações com a saúde mental. Temas em Psicologia, 24(1), 205-218. https://doi.org/10.9788/TP2016.1-14

Pellegrino, H. (1986). Psicanálise da criminalidade brasileira. In P. S. Pinheiro \& E. Braun (Orgs.), Democracia $x$ violência: Reflexões para a Constituinte (pp. 96-110). Paz e Terra/ Comissão Teutônio Vilela.

Rebelo, T., \& Thomas, M. (2016). O trabalho de narratividade com adolescentes em uma residência terapêutica. In T. K. Brasil \& D. Drieu (Orgs), Mediação, simbolização e espaço grupal (pp. 152-171). Liberlivros.

Rocha, M. C. (2011). Plantão psicológico e triagem: Aproximações e distanciamentos. Revista do NUFEN, 3(1), 119-134. http:// pepsic.bvsalud.org/scielo.php?script $=$ sci arttext\&pid=S217525912011000100007\&lng=pt\&tlng=pt.

Scisleski, A. C., Coelho, B., Galeano, G. B., Santos, S. N., \& Silva, J. L. C. (2015). Medida socioeducativa de internação: Estratégia punitiva ou protetiva?. Psicologia \& Sociedade, 27(3), 505515. https://doi.org/10.1590/1807-03102015v27n3p505

Vidal, A., Freitas, J., \& Oliveira, M. (2017). Medida de prestação de serviços à comunidade: Responsabilização, educação e liberdade. In M. C. Craidy \& K. Szuchman (Orgs.), Socioeducação: Fundamentos e Práticas (pp. 191-203). Editora da UFRGS.

Waiselfisz, J. J. (2015). Mapa da violência: Adolescente de 16 e 17 anos no Brasil. Flacso. http://www.mapadaviolencia.org. br/pdf2015/mapaViolencia2015_adolescentes.pdf 